\title{
Theme-Attraction and Bound Verbs in Southern Wakashan
}

\author{
John Stonham \\ Pukyong National University, Korea
}

\begin{abstract}
The present article addresses the issue of the existence of noun incorporation in the Southern Wakashan languages of the Pacific Northwest. There have been a number of proposals for treating a process in the languages that combines elements of a theme argument with a bound verbal element. None of these previous treatments account for the full range of data surrounding this phenomenon in this family of languages. This article introduces new data from all of the Southern Wakashan languages, demonstrating that this is a property of the entire family and provides a new
\end{abstract}

\footnotetext{
$\S$ This work was supported by a Research Grant from Pukyong National University (2018).

John Stonham

Professor, Department of English Language and Literature, Pukyong National University, Korea Email: stonham@pknu.ac.kr

Received 24 January, 2019; Revised 19 February, 2019; Accepted 25 February, 2019

Copyright (C 2019 Language Research Institute, Sejong University Journal of Universal Language is an Open Access Journal. All articles are distributed online under the terms of the Creative Commons Attribution Non-Commercial License (http://creativecommons.org/licenses/by-nc/3.0) which permits unrestricted non-commercial use, distribution, and reproduction in any medium, provided the original work is properly cited.
} 
analysis of this phenomenon that makes use of a feature of theme attraction that may be associated with select verbal elements in all three languages. This feature, combined with a distinction between verbal suffix and bound verb, suggests a new and more general account of the facts of the process. When combined with the recognition of the thematic parallelism between transitive objects and unaccusative subjects, this leads to a new and general account of the facts of the process of combining elements of the theme argument with bound verbs in Southern Wakashan languages.

Keywords: incorporation, unaccusative verb, Southern Wakashan language, bound verb, affixation, theme role, attraction

\section{Introduction}

The Southern Wakashan languages (henceforth SW) are a family of languages spoken in the Pacific Northwest of North America. The family consists of three languages located from north to south geographically: Nuuchahnulth, Ditidaht, and Makah. ${ }^{1}$ All three are in advanced degrees of endangerment, but there exist textual materials of all of them that record earlier, more viable stages of the languages. These languages constitute the central focus of this study.

There has been a longstanding debate among linguists as to whether the SW languages make use of a process of noun incorporation, which involves moving or 'incorporating' an object noun into the verb, thereby forming a single unit (Stonham 1998, Wojdak 2003). The basic facts are as in (1) below.

\footnotetext{
1 While the Northern Wakashan branch of the family is also claimed to exhibit similar properties, the inclusion of this branch is beyond the scope of this study. For discussion of the Northern branch, see Caballero et al. (2008). Ethnologue 21 (Simons \& Fennig 2018) rates the status of Nuuchahnulth and Ditidaht as category $8 \mathrm{~b}$ (nearly extinct) and Makah as category 9 (dormant).
} 
(1)
a. $[\text { ?u-na k-ši-Pað }]_{\mathrm{V}} \quad[\text { tana }]_{\mathrm{NP}}$
EXPL-have-PRF-NOW child
'she had a child'

b. $\left[\text { tanăa }_{\mathrm{i}}-\mathrm{nak}-\mathrm{s} \mathrm{i}-\mathrm{Pa} \chi\right]_{\mathrm{V}} \quad\left[\mathrm{t}_{\mathrm{i}}\right]_{\mathrm{NP}}$

'she had a child'

${\text { (Nuuchahnulth })^{2}}^{2}$

(1a) shows the bound verbal, $-n a k^{w}$ 'have' combined with a semantically-empty, filler base, $? u$, to render the meaning of 'have' as a free word followed by the object NP tana 'child', while (1b) demonstrates the combination of tana 'child' with the bound verbal -na $k^{w}$ 'have', rendering the meaning 'have a child' in a single word.

Kroeber (1910) in his paper 'Noun Incorporation in American Languages' states that "[n]oun incorporation is the combination into one word of the noun object and the verb functioning as the predicate of a sentence. It is essential that the resultant of incorporation is a single word, else the process is without limit and all syntactical relation may be construed as incorporation." Based on this definition and the data in (1), one might easily conclude that the phenomenon in SW is, in fact, an instance of incorporation.

More recently, Massam (2017) has described noun incorporation as follows: "Noun incorporation (NI) is a grammatical construction

\footnotetext{
2 The sources of data are discussed in the following section. Abbreviations employed in this paper include CAUS causative, CLF classifier, DEF definite, DIM diminutive, DUP reduplicative copy, EXPL expletive base, IND indicative mood, INTENT intentive mood, NOW contemporaneous action, PASS passive, POSS possessive, PST past tense, PRF perfective aspect, QUOT quotative, [R] reduplication required, SUB subordinate mood. Morpheme analysis follows the conventions of the Leipzig Glossing Rules.
} 
where a nominal, usually bearing the semantic role of an object, has been incorporated into a verb to form a complex verb or predicate." This definition is more detailed in substance, including the notion of semantic role and the reference to nominal/verbal elements, allowing for different interpretations of the status of these elements.

The process of incorporation, by definition, is syntactic in nature, involving movement of an element defined as an object into a verb, described by Massam as a grammatical construction. What we will see in this paper, with respect to SW, is that there are also elements of phonological/morphological involvement in this process. Furthermore, while the operation may, at first glance, seem to move the object into the verb, further examination reveals that this is only part of the story.

The main issues to be discussed in the remainder of this paper are: (1) does the phenomenon found in SW constitute an instance of noun incorporation? (2) if it is not incorporation, what is it? and (3) how do we analyze this phenomenon?

\section{Background and Sources}

Data for the research underpinning this paper has been assembled into several databases consisting of textual material that has been morphologically analyzed and translated. Each database investigates one language from the SW group and consists of a collection of analyzed texts and a lexicon that is used for the analysis and translation of that language. Databases of Nuuchahnulth and Ditidaht are already in advanced stages of development, while the textual database of the third language, Makah, is in a more preliminary stage. We will examine each of the databases below.

Nuuchahnulth, spoken on the upper west coast of Vancouver Island, is the most viable of the three endangered languages and has the 
greatest amount of textual material collected, beginning in the early 20th c. ${ }^{3}$ The main source of data are the fieldnotes of Edward Sapir, collected in the period from 1911 until 1916 and the subsequent materials sent to Sapir by Alex Thomas, a native speaker of Nuuchahnulth, until 1922 (Sapir n.d.). These materials, provided by speakers born in the mid to late 19th c. provide the earliest reliable source of data from any of these languages and, thus, the best source of information on SW. The Nuuchahnulth textual database currently consists of over 165,000 words taken from over 150 texts of varying length and subject matter. In addition to this invaluable source, data has also been drawn from the study by Rose (1981) for the northerly Kyuquot dialect and from Nakayama (2003) on the central, Ahousaht dialect.

The second database contains textual material principally drawn from the fieldnotes collected by Mary Haas and Morris Swadesh in 1931 from the Ditidaht people of southwestern Vancouver Island (Haas \& Swadesh 1931). These materials are supplemented by data collected in the 1960s-1970s resulting in a database consisting of approximately 32,000 words, providing a number of examples of the phenomenon under study. The Ditidaht textual database consists of over 100 texts of varying length and subject matter, drawn from consultants born in the late 19th century, at a time when the language still had monolingual speakers. In addition to this, data has been drawn from the unpublished grammar of Thomas \& Hess (1981).

Finally, the least developed database of these three languages is that of Makah, consisting of some 10,000 words in about 3,300

${ }^{3}$ Earlier studies of all of the SW languages exist but are too linguistically unsophisticated to be considered reliable records of the languages. (See, for example, Moziño 1793, Knipe 1868, Swan 1870, etc.) 
sentences collected by William H. Jacobsen, Jr. in the 1960s-1980s (Jacobsen n.d.). The speaker/consultants for this work were clearly of a younger generation that the two other studies and the data is less extensive. The Makah textual database is still in early stages of development. These are the earliest textual materials gathered on Makah and are unfortunately from a time when the language is already in decline. On the positive side, there are audio recordings for the Makah materials, making it possible to confirm the quality of the transcriptions of the materials.

All three languages exhibit the characteristics to be discussed here, but data from Nuuchahnulth, being more extensive and coming from an earlier time period will be the most heavily relied upon here and will be supported by data from the other two languages.

\section{The Phenomenon}

We begin the examination of this process with an exposition of a few basic facts about SW languages that bear directly on this phenomenon, beginning with a presentation of the facts of word order in the languages.

\subsection{Basic Word Order in Southern Wakashan}

SW languages all demonstrate a similar, basic Verb-SubjectObject word order, as indicated by the examples below. ${ }^{4}$

${ }^{4}$ It should be noted that this data may be further analyzed into morphemes consisting of roots and suffixes. Morphological breakdown will be provided where germane to the data. 
(2) a. Verb

גawiiči?aג

he approached

'The young man approached his mother'
Object

PumPiiqsak

his mother

\section{Subject}

haawiłax?is?i

the young man

(Nuuchahnulth)

b. Verb Subject

Object

גawe ?iyuw

q $^{w}$ e'tiy

qała takk ${ }^{\mathrm{w}} \mathrm{aq}$

he approached Mink

his younger brother

'Mink approached his younger brother'

(Ditidaht)
c. Verb
Subject
Object
tu'pukwax
Pabe' ?iqs
ha?ub?iq
she was happy
the mother
the food
'The mother was happy now for the food'

(Makah)

These examples demonstrate the basic word order for all three languages, with the verb being initial in the sentence, followed by the subject NP, and then the object NP. It should be noted, however, that overt subject and object NPs are rarely found to co-occur on the surface, as noted by Rose (1981: 38): "Although transitive predicates with two surface adjuncts are not prohibited, they are rare in Kyuquot. Transitive clauses normally have only one surface adjunct, due to pronominalization and ellipsis of either the subject or object."

In addition to sentential word order, NP internal word order may be relevant to the investigation here and follows the pattern in (3).

(3) Quantifier (+ Clf) > Adjective > Noun > Relative Clause

An example of a complex noun phrase containing multiple elements of the noun phrase is provided in (4) below. Note that this case involves a copular predicate attached to the initial element of the NP, 
due to cliticization of inflection to the initial member of the NP. This structure is distinct from the process under study here and is provided simply to illustrate the order of elements in the NP. ${ }^{5}$

(4) $\left[[\text { nup-saath }]_{\mathrm{i}}-\mathrm{e} \text { ic }\right]_{\mathrm{V}}\left[\left[\mathrm{t}_{\mathrm{i}}\right]_{\mathrm{CLFP}}\left[[\text { iii }]_{\mathrm{ADV}}[\text { wikPaỷaq } \chi]_{\mathrm{ADJ}} \text { maPas }\right]_{\mathrm{N}}\right]_{\mathrm{NP}}$ $\uparrow$

one-...tribe(s)-2s.IND

very

stupid tribe

'you are one very stupid tribe'

(Nuuchahnulth) ${ }^{6}$

The AdjP may contain an initial adverbial modifier, such as Piit 'very', followed by one or more adjectives, as shown in (4).

\subsection{Free versus Bound Verbs in Southern Wakashan}

All SW languages make extensive use of an exceptionally large pool of bound morphemes to build complex words consisting of a single root morpheme combined with zero or more bound morphemes attached after the single root. Examples include those in (5). ${ }^{7}$

a. cawaa-?ath-inỷ-ap̉-a $\mathfrak{x}^{2}$-at-we?in

one-live at-leave behind-CAUS-NOW-PASS-3.QUOT

'she was left behind living all alone, it is said'

(Nuuchahnulth)

5 In general, SW allows copular predicates consisting of some element of a NP fronted into the inflectional clitic complex without any overt verbal element (Rose 1981: 55). Such copular predicates should be considered a separate issue from the process under discussion in this paper.

${ }^{6}$ CLFP represents Classifier Phrase, the combination of quantifier with the appropriate noun classifier, which is determine by the head of NP.

7 See Davidson (2002) on the inflectional clitic complex in SW, which includes person/mood/tense marking on the verb. 
b. łu-tč-it $\chi$-abi-?s-ibt-uw

DUP-woman-look for...[R]-move about-on ground-PST-3.QUOT

'he was going about looking for a woman'

(Ditidaht)

c. ya'daq-dak-šì̉-e ?is-að-qa

baby-have-PRF-INTENT-NOW-3.SUB

'that she intended to have a baby'

(Makah)

These examples are intended to illustrate the high degree of polysynthesis in all of these languages but, in addition, they provide examples of bound verbs, -?ath 'live at' in Nuuchahnulth, -atax 'look for' in Ditidaht, and $-d a k^{w}$ 'have' in Makah. This operation will be referred to pre-theoretically as verb-argument composition (Stonham 2008), indicating that it involves a verbal unit in composition with some unspecified argument of the verb. This usage avoids committing to combination with only the object, which is the standard description of noun incorporation, since it is clear that certain types of subjects also participate in the process and is also ambiguous as to the status of the bound verbal, to be discussed anon. It furthermore sidesteps the issue of whether this involves compounding, incorporation, etc., at least for the time being.

Note that none of these bound verbs may stand alone as the first element of the word, the only possible element that may do so being a reduplicative copy of the root, as shown in (5b). It is possible for bound verbs to appear without a preposed lexical root, combining instead with a semantically empty, expletive root, $? u$, acting as a placeholder for the bound verb, as discussed in Stonham (1998), illustrated below (6-8). 
(6) Nuuchahnulth
a. Verb
?u-naak-ši-?a入
Object
EXPL-have-PRF-NOW
tana

'She had a child'

b. Verb

tana-nak-ši-?aג

child-have-PRF-NOW

'She had a child'

(7) Ditidaht
a. Verb
Pu-da'k-uw
Object
EXPL-have-3.QUOT
buša?
'He had a fish-weir'
fish-weir

b. Verb

bušu-da'k-šð-uw

fish weir-have-PRF-3.QUOT

Subject

$\dot{\mathrm{q}}^{\mathrm{w}} \mathrm{e} \cdot \mathrm{ti}$

'Mink had gotten a fish-weir'

(8) Makah
a. Verb
Object
?u-da'k-ši $\chi$
Pada'k
EXPL-have-PRF fire
'he got fire'
b. Verb
Piki'-dak-š-?ax
son -have-PRF-NOW
'he got a son' 
The only elements that may precede a bound verb are: (i) the expletive base $\mathrm{Pu}$, or (ii) an element of a [+Th] argument.

\subsection{Expletive $? u$}

With respect to the expletive base $? u$, as in the (a) examples in (68 ) above, it should be noted that it is highly restricted in terms of its co-occurrence in SW. ${ }^{8}$ Based on its position of occurrence, $? u$ behaves as a root, occurring on the left edge of the word, since there are no prefixes in SW. However, unlike other roots in SW, it never stands alone, with or without inflectional morphology, but must always be combined with a lexical element that presumably provides meaning for the resulting word. Roots in SW in general combine with a wide range of elements, including bound verbal elements, locatives, nominalizers, etc., but $? u$ is restricted to combination with bound verbs. $? u$ is semantically empty and has no subcategorization requirements of its own beyond a necessity to combine with a bound verbal. No other root exhibits such a requirement, making $? u$ unique in this respect. Any combination of $? u$ with another element results in the valency and semantic content of the combining element with no contribution from $? u$ other than as a placeholder.

$? u$ should be treated as a semantically empty, morphologically necessary element, much as English weather verbs require an obligatory expletive it in syntactic structures like it's raining, as in (9a).

${ }^{8}$ Conversely, in terms of actual occurrence, $? u$ appears as the base in over $10 \%$ of all word types in the Nuuchahnulth database, highlighting its importance in word formation. Results for the other SW languages are similar. 
(9) a. It's raining.

b. It snowed yesterday.

c. ${ }^{*} \varnothing$ snowed yesterday.

Just as English it in weather verbs is not semantically active but is necessary to fulfill syntactic well-formedness requirements on subjects (9c), so ? $u$ in SW is semantically inert, but is required morphologically to license a bound verb as a free verb.

It has been claimed in Mithun (1984: 888) that instances such as $-n a k^{w}$ versus Puna $k$, constitute a formal etymological relationship between bound verb versus free root. However, this should not be viewed as an etymological relationship but rather as a morphological relationship between bound verb and expletive base. Such an approach is necessary to explain the appearance of the bound verbal as a freestanding element in the case where it is not combined with some member of the $[+\mathrm{Th}]$ argument. One can find literally dozens of pairs of the type referred to by Mithun in the Nuuchahnulth data, and in the data from the other SW languages. This is due to the fact that the combination of $? u$ with a bound verbal is the sole means to create a free form from a bound verb. In fact, there are numerous examples in SW of etymologically unrelated free verb/bound verb pairs, as attested in (10), taken from Nuuchahnulth.

$\begin{array}{llll}\text { Meaning } & \text { Free Root } & \text { Pu+Bound Verb } & \text { Bound Verb } \\ \text { 'cry' } & \text { Giћ } & \text { Pu-Puu-yuk } & \text {-ayuk } \\ \text { 'buy' } & \text { mak }^{\mathrm{w}} & \text { Pu-haa } & \text {-haa } \\ \text { 'eat' } & \text { ha?uk } & \text { Pu-Piis } & \text {-'is }\end{array}$

9 This bound verb, and others like it, require reduplication of the initial CV of $? u$ or whatever base they attach to. 
(11)

a. haPuk ${ }^{\mathrm{w}}-\mathrm{a} \chi \quad \dot{\chi}^{\mathrm{\lambda}} \mathrm{aaq}-\mathrm{aašt}$

eat-NOW blubber-dried...

'they ate dried blubber'

b. ?u-Piis-?aג

Pusiti-?i

EXPL-eat-NOW body-DEF

'they ate the body'

(Nuuchahnulth)

As can be seen in the data in (10) and the example in (11), there are free roots that share the same or similar meanings with bound verbs and with the free roots that result from combining bound verbs with $? u$. Combining with $? u$ does not affect the valency or the semantic properties of the bound verb.

\subsection{Verb Suffix versus Bound Verb}

It is important to recognize that bound verbals in these languages are distinct from what Rose (1981), and Sapir \& Swadesh (1939) before, refer to as restrictive verbal suffixes (VRA), as Rose states.

If a predicative stem is composed of a nominal base and a VRA, the base is interpreted as a predicative NP coreferential to its subject and dominating a verbal predicate. (486) tuhtu'psuћt There's a scary monster coming out of the woods /tuh-(̌s)tu'p-(c)suhta/ afraid-..thing-come out of woods

(Rose 1981: 320)

Unlike with bound verbals, this does not mean "[a scary monster $]_{\mathrm{NP}}$ [came out of the woods] vP" but rather "there is [a scary monster that is coming out of the woods $]_{\mathrm{NP}}$ ". Compare this case with the one below 
(12) which involves a bound verb, -wahsut 'come out'.

čif-waћsut-?aała

supernatural being-come out-always

'[A supernatural being $]_{\mathrm{NP}}$ [always comes out $]_{\mathrm{VP}}$ '

(Nuuchahnulth)

One further indicator of the difference between these two types of verbal morphemes is the fact that the expletive base, $? u$, is only

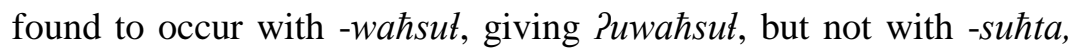
thus *?usuhta. This echoes Rose (1981)'s distinction of governing versus restrictive verbal elements and supports the characterization of morphemes like -wahsut as bound verbs.

The elements involved in verb-argument composition are often described as suffixes, and therefore involve simple affixation but, in fact, there are several properties that distinguish these elements from typical affixation. Before introducing these properties, we may consider the more well-known case of English bound verbs, such as mit or -ceive. As Katamba \& Stonham (2006: 45) observe:

Many roots are incapable of occurring in isolation. They always occur with some other word-building element attached to them. Such roots are called bound morphemes. Examples of bound morphemes are given below:

(3) a. -mit as in permit, remit, commit, admit

b. -ceive as in perceive, receive, conceive, deceive

c. pred- as in predator, predatory, predation, depredate

d. sed- as in sedate, sedent, sedentary, sediment

As the examples above demonstrate, cases such as these cannot be considered to be affixes, in spite of the fact that they depend on 
another element. For one thing, if we treat these as affixes, and the elements that appear with them are also affixes, we have the decidedly unappealing consequence that the resulting words would have no roots, a theoretically unpalatable result.

Furthermore, other bound roots arise in English in the case of Neoclassical compounding. For example, the bound root iatr 'heal', found in iatro-phobe and ger-iatr-ic, may be either the first or last root of a compound. In such cases, compounding is necessary in order to create a free base from the combination of bound roots. All of the above cases should make us wary of simply assuming affixhood based on position in a word. They also require that we include in the description of these morphemes a means to indicate whether they are left-bound (-mit, -ceive), right-bound (pred-, sed-), or bound on either edge (iatr).

To return to SW, there are several crucial differences between bound verbs and verbal modifier suffixes. First of all, bound verbs act as the head of the verbal construct, as discussed above and exemplified in (12 and 13a). Verbal suffixes serve to modify the meaning of a root, as shown in (13b and 14).

a. Bound verb

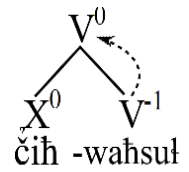

b. Restrictive Verbal suffix

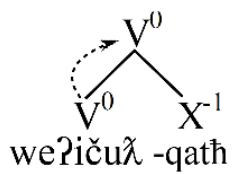

a. we?ič-uג-qath-?aג sleep-PRF-pretend to-NOW 'he pretended to fall asleep' 
b. çu-bat-abł wash-move around-over surface 'wash (e.g., a car)'

(Ditidaht)

c. ta'-padač-š-?a drift-move about-PRF-NOW 'he was drifting about'

Note here that the semantic head in (14a) is we?ič 'sleep' and it is modified by -qath 'pretend'. In (14b) the head is $c u$ 'wash' and it is modified by -bat 'move around'. Finally, in (14c) $t a$ ' 'drift' is the semantic head, and -padač 'move about' modifies this head. All these verb suffixes perform a modifier function, subordinate to the main verbal sense of the word.

In all of these cases we can see that the verbal suffix simply modifies the meaning of the root in some way, i.e., 'pretend' modifies the action of sleeping, 'move around' specifies a kind of washing, and 'move about' enhances the sense of drifting.

A second way in which bound verbs differ from verbal suffixes is that only bound verbs may co-occur directly with the expletive base $? u$, as shown in $(6 \mathrm{a}, 7 \mathrm{a}, 8 \mathrm{a})$ above. Verbal suffixes, on the other hand, cannot co-occur in the way, thus *?uqath 'pretend to' or *?ubat 'move around' or *?u'padač 'move about'. This makes complete sense if $? u$ is semantically empty and unable to contribute any kind of subcategorization to the whole word. In such a context, bound verbs, which act as heads and do provide subcategorization, may combine with ?uto construct a well-formed word with proper subcategorization. $? u+$ verbal suffix, e.g., -qath/-bat/-padač, on the other hand, cannot form a complete word since they do not possess subcategorization, resulting in an ill-formed word.

Finally, we have already seen that bound verbs may combine with 
an element of the object, but verbal suffixes never do. This further supports the position that bound verbs have subcategorization properties and valency requirements, whereas verbal suffixes do not, behaving more like modifiers of the main verb. This reflects the use by Rose (1981) of the term 'restrictive'. All of these properties suggest a clear, fundamental difference between bound verbs and verbal suffixes in SW.

\section{Previous Analyses}

There have been a number of previous treatments of the data under investigation here, going back to Rose (1981)'s treatment of the northernmost Kyuquot dialect of Nuuchahnulth. In her study she refers to the class of bound verbal elements that participate in this process as "governing" suffixes, as opposed to "restrictive" suffixes which merely modify the base to which they attach. ${ }^{10}$ Rose (1981: 294) observes that the order of the elements within the NP is Quantifier > Quantity > Adjective > Noun. This may be the first exposition of the facts of SW verb-argument composition and it notes the fact that so-called incorporation involves only an element of the object NP, not necessarily the noun itself. This contradicts the expectation of Massam (2017) that: "[noun incorporation] refers to a grammatical phenomenon whereby a nominal element, usually with an internal thematic role, forms some kind of unit with a verbal element, and together they serve as the verb or predicate of a sentence." Clearly, the latter requires a noun to be combined with the verb, not simply an element of the NP.

10 This terminological distinction in Nuuchahnulth originates with Sapir \& Swadesh (1939). 
Stonham (1998) investigates the nature of the incorporation of numerals and the role of classifiers in the SW system. In that study it is demonstrated that the quantifier, as first element in the object NP, may be conjoined with the bound verb in Nuuchahnulth (cf. (15b) below for an example from Ditidaht). The most relevant aspect of this is that this operation does not fit the standard definition of noun incorporation, as defined above.

Wojdak (2003: 275-6) refers to the bound verbs as morphologicallybound transitive predicates which incorporate their objects via a process of cliticization, claiming that they are transitive predicates that incorporate their objects. While Wojdak refers to the process as cliticization, there is no evidence in SW that any of the elements involved in this process are clitics, so this is a rather novel claim. Furthermore, the author refers only to objects as the target of incorporation with no mention of what element within the object may be incorporated. Finally, there is no discussion of the possibility that subjects may also be involved, a topic that will be discussed in Section 5.1.

Subsequent to this paper, Wojdak (2005: 129) revises her analysis, stating that "Nuu-chah-nulth affixal predicates incorporate their object, and not their subject." This further misses crucial aspects of the process that occurs in Nuuchahnulth and in the other SW languages, specifically: (i) it is not the entire object that is incorporated, as has been noted as early as Rose (1981) above, and furthermore, (ii) it is not always the object which provides the target of the process. This latter fact will be discussed in more detail in Section 5.4.

Johns (2017), in her paper on 'Noun Incorporation', observes that "Nuu-chah-nulth is an obligatorily incorporating language. In these languages, the more general class of predicates never incorporates a nominal [...] The second set of predicates are a finite set, which obligatorily incorporate." The issue of the obligatoriness of this 
process will be relevant to the discussion in Section 5.3.

On the other side of the incorporation argument, Davidson (2002: 92) states for both Nuuchahnulth and Makah that "[t]here is no prefixation (apart from reduplicative prefixes), compounding, or noun incorporation." Davidson goes on in a footnote to state that "[a]ctually, the question of whether Makah, Nuuchahnulth, and other languages with lexical verbalizing suffixes can be characterized as incorporating is controversial. I am agreeing with the view expressed by Sapir (1911) and Mithun (1984), among others, that these languages are not incorporating." Davidson does not clarify what exactly is involved in the process that produces such combinations of verb and argument element, but his reference to Jacobsen (1993: 266-67, note 2) suggests that this process may be a type of denominal verb formation. ${ }^{11}$ This may be closer to the facts, but still runs into problems with Rose (1981)'s original observation concerning the element combined with the verb, as discussed at the beginning of this section.

This absence of agreement on the nature of the process highlights the complexity of the arguments arising from the SW data discussed here. We will clarify the reasons for the confusion below and provide a way forward on this rather complex process as it occurs in SW by examining data from the three languages.

\section{The Analysis}

In this section we consider an alternative approach to the analysis of the facts presented above. We begin by examining possible alternative analyses and showing why they are, in some way, inaccurate or incomplete. We then introduce the notion of theme

11 See Stonham (2008) for a more detailed exposition of this position. 
attraction as a feature of bound verbs. Finally, we address the relationship between transitive and unaccusative verbs.

\subsection{Incorporation}

To answer the first question raised in the introduction, the process that is found to occur in SW is clearly not simply a case of noun incorporation. There are at least the following three ways in which this operation is distinct from noun incorporation:

1) It doesn't only target the head noun of the object-it selects the first available element of the [+Th] argument

2) It doesn't only target object NPs - elements from unaccusative subjects may also combine with the bound verb

3) It doesn't saturate V subcategorization - in many cases, the remainder of the argument remains in situ with its assigned thematic role

The first point is that, in the case of noun incorporation, one should expect that it is a noun that is moved into the verbal complex, as discussed by linguists from Kroeber (1910) to Massam (2017). Irrespective of the valency of the verb, in SW the bound verb does not necessarily combine with the head noun of the direct object, but instead targets the first element of the [+Th] argument, as shown in (15). This may be the head noun, as in (1b) above, but it may be other elements of the [+Th] argument. (15a) demonstrates the movement of an adverbial modifier, $2 i \hbar \hbar$ 'very', of an adjective, $\lambda u t$ 'good', out of the object 'very good canoe' into the verb -itt 'make'. (15b) shows the movement of a quantifier, ?az 'two', into the verb -e'yip 'obtain', leaving behind the head noun $q i$ 'wa 'steelhead trout'. Finally, $(15 \mathrm{c})$ indicates the movement of an adjective, $\lambda a^{2} u$ ' 'other', into the 
verb - $d a k$ 'have'. All of these cases demonstrate that the process involved here does not simply target the object head noun, as would be expected if this was noun incorporation.

a. $\left[\mathrm{Pii \hbar \hbar}_{\mathrm{i}}-\mathrm{iil}\right]_{\mathrm{V}} \quad\left[\begin{array}{lll}\mathrm{t}_{\mathrm{i}} & \chi \mathrm{u} & \left.\text { čapic }]_{\mathrm{NP}}+\mathrm{Th}\right]\end{array}\right.$

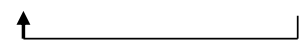

very-make good canoe

'he made a very good canoe'

(Nuuchahnulth)

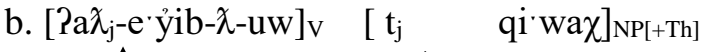

two-obtain-NOW-3.QUOT steelhead trout

'he got two steelhead trout, it is said'

(Ditidaht)

c. $\left[\chi \mathrm{a}^{2} \mathrm{u}_{\mathrm{k}}-\mathrm{dak}-\mathrm{a} \chi\right]_{\mathrm{V}} \quad\left[\mathrm{t}_{\mathrm{k}} \mathrm{la}^{\prime} \chi \mathrm{uk}^{\mathrm{w}}\right]_{\mathrm{NP}[+\mathrm{Th}]}$

$\uparrow$

other-have-NOW man

'they had another man'

(Makah)

All of these examples clearly show that the target of movement is the first, or leftmost, element of a [+Th] argument of the verb, regardless of word class, attesting to the local nature of this process. This clearly does not fit the expectation of a case of noun incorporation, which focusses on the head noun as the sole target of movement. In fact, the noun in this phenomenon is the last possible candidate for movement, given its syntactic position within the noun phrase.

The second point relevant to the case of noun incorporation concerns the role of unaccusative verbs, which are monovalent and, therefore, have no object to incorporate. While Kroeber (1910) refers specifically to the object noun, and a number of others have followed this lead, Massam (2017) is more circumspect, referring to a nominal 
element, usually with an internal thematic role, that forms some kind of unit with a verbal element. This characterization of the process allows for a slightly broader interpretation of the process, although it still refers to a nominal element, which does not conform to the data in (15) or the discussion above.

Die is a prototypical monovalent unaccusative verb and, thus, a good choice for testing the scope of this operation. As can be seen by the data in (16) below, the subject NP of an unaccusative verb, or the first element thereof, may be combined with the bound verb in the same way that the first element of a $[+\mathrm{Th}]$ direct object of a transitive verb is targeted, as in (1) and elsewhere.

a. $\left[{\left.\text { Sił } \check{c}_{\mathrm{i}}-\mathrm{Suu} \chi\right]_{\mathrm{V}}}\left[\mathrm{t}_{\mathrm{i}}\right]_{\mathrm{NP}[+\mathrm{Th}}\right]$

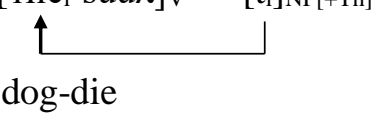

'A dog is dying'

(Nuuchahnulth)

b. $[\text { ?ayaj-si'w }]_{\mathrm{v}}\left[\mathrm{t}_{\mathrm{j}} \mathrm{qu} \cdot \mathrm{Pas}\right]_{\mathrm{NP}[+\mathrm{Th}]}$

ఓ

many-die people

'many people died'

(Ditidaht)

c. $\left.\left[\mathrm{du}^{\prime} \mathrm{ba}_{\mathrm{k}}-\mathrm{siwi \chi}\right]_{\mathrm{V}}\left[\mathrm{t}_{\mathrm{k}} \mathrm{wi} \cdot\right]_{\mathrm{NP}+\mathrm{Th}}\right]$

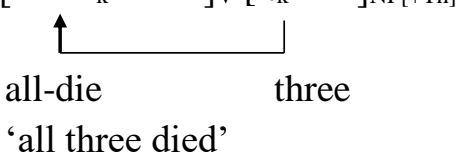

As we can see from the data in (16), an element of the subject NP of an unaccusative bound verb, following the same order of selection as with transitive objects, may be combined with the verb. In (16a), it is the sole member of the NP, the head noun, that is combined with 
the verb, while in (16b) it is the adjective modifying the head noun that moves into the bound verb. In (16c), we see a quantifier, $d u \cdot b a$ 'all', that combines with the verb.

Finally, the third point introduced above is that the combining of an element of the [+Th] argument with a bound verb does not saturate the subcategorization of the verb. Instead, it simply satisfies the requirement that the combining element originates in the $[+\mathrm{Th}]$ argument. For this reason, the remainder of the argument may still appear, as shown in (15). All of the examples in (16) exhibit head nouns remaining in situ, where, by the theta criterion (17), they would necessarily be marked as [+Th]. The fact that the extracted element is separated from the remainder of its [+Th] argument poses no problem to the verb's subcategorization.

(17) $\Theta$-criterion: Each argument bears one and only one $\theta$-role, and each $\theta$-role is assigned to one and only one argument.

(Chomsky 1981: 35)

All of these facts argue against any analysis that considers this process to involve incorporation, answering the first question posed in Section 1.

\section{2. $[+\operatorname{Attr}(\operatorname{act}) \operatorname{Th}(e m e)]$}

In what follows, we address the other two questions raised in Section 1, i.e., if this process is not incorporation, what is it? and how do we analyze this phenomenon? To answer the first of these two questions simply, the process involves Theme-attraction. This feature will be discussed in more detail below.

There are two main issues that must be addressed in order to provide a proper treatment of the combining of the verb with an 
element of the theme argument: (i) the issue of bound versus free verb and (ii) the unification of the treatment of unaccusative and transitive bound verb arguments.

We have seen in Section 3.3 that there is good reason to distinguish verb suffixes from bound verbs in SW. Assuming this distinction is correct, we must now consider the distinction between bound and free verbs. To begin with, it should be noted that bound verbs are morphologically defective or incomplete, and may not stand on their own, just as English bound verbs like -mit or -ceive cannot stand on their own, as discussed in Section 3.3. In either case, bound verbs may be freed by combination with another morpheme. This is accomplished in English by the attachment of a member of a limited set of prefixes, such as re-, con-, etc. In SW, this 'freeing' of the bound verb may be achieved by the attachment of the expletive base, $? u$. This combination renders bound verbs equivalent to free verbs and satisfies the requirement to combine the bound verb with an element of an argument of the verb. If bound verbs are not made into free verbs by combination with $? u$, then they may be lexically inserted under $\mathrm{V}$, marked as $\mathrm{V}^{-1}$ to indicate their status as bound.

In addition to the bound nature of verbs lexically inserted under $\mathrm{V}^{-1}$, there is a further consideration that accompanies the bound verb. This involves subcategorization. All verbs, whether free or bound, come with a subcategorization requirement, depending on their valence. Verbs like die, sleep, etc. in English require only a subject, while verbs like eat, see, etc. require both a subject, which is an agent, and an object, which is typically a theme. This same is true for SW verbs.

Where SW diverges from English is in the treatment of bound verbs. Bound verbs behave just like free verbs, except in one key respect. Free verbs are, by definition, unbound to any external elements beyond the typical subcategorization requirements. On the other hand, bound verbs in SW possess, in addition to the 
subcategorization requirements, an additional feature of theme attraction. This requires that some element of the theme argument be merged with the bound verb.

This feature, [+Attr(act)Th(eme)], occurs together with the typical subcategorization requirements of verbs, which may require only a subject (intransitive), or a subject and direct object (transitive), or other possible arguments. The [+AttrTh] feature on a bound verb may be satisfied in the lexicon by combination with $? u,{ }^{12}$ resulting in a free verb. If the bound verb with [+AttrTh] feature is basegenerated in the syntax however, it can only be satisfied by an element of a theme argument adjacent to V. This element, the first available word within the theme argument following the required NP word order, is preposed to the bound verb under V. In this way, it satisfies the requirement of the feature, filling the empty slot adjacent to the $\mathrm{V}^{-1}$ under $\mathrm{V}$. If this [+AttrTh] position is not filled, the result is ungrammaticality.

(18) Bound Verb:

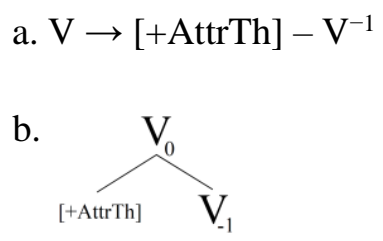

Bound verbs constitute a special class of verbal elements in SW that are distinct from verbal suffixes. Only bound verbs exhibit the special feature of theme attraction, $[+\mathrm{AttrTh}],{ }^{13}$ a property that targets

\footnotetext{
12 Presumably, $? u$ possesses the [+Th] feature that fulfills the requirements of [+AttrTh].

${ }^{13}$ According to the Utrecht Lexicon of Linguistics, an attractor is "the uninterpretable (inherent) feature which attracts a matching feature (in order to be deleted)."
} 
certain elements in the sentence, moving an element into the verbal complex. The theme argument has the same configuration for free or bound verbs, but the verb itself reflects the differences between them, as shown in (19).

a. $[+\mathrm{Th}]$ argument of bound verb

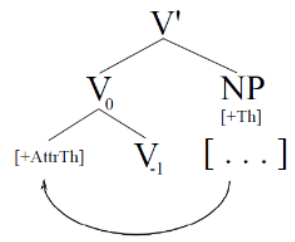

b. $[+\mathrm{Th}]$ argument of free verb

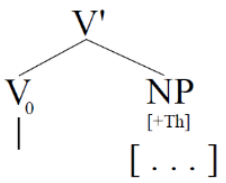

This feature explains the obligatoriness of the movement which has previously been referred to as obligatory incorporation, e.g., in Johns (2017) cited in Section 4. If this feature is an inherent property of this type of bound verb in SW, then it must be satisfied in one of two ways. The feature mus either be saturated by combining with $? u$ in the lexicon or it must be lexical inserted under V. In the latter case, this is followed by extraction of an element of the theme argument and subsequent movement into the bound verbal complex.

Like any other grammatical feature, [AttrTh] must be satisfied in order to produce a properly licensed outcome. Bound verbs that do not combine with $? u$ in the lexicon must necessarily be licensed by a syntactic operation postlexically. The element that licenses the bound verb cannot be moved into $\mathrm{V}$ until it has first been lexically inserted into the $[+\mathrm{Th}]$ argument of the verb in its appropriate place, depending on its syntactic category. In other words, this operation cannot take place until there is a wellformed VP from which to extract an element of the [+Th] argument. This feature appears prominently in all three languages of the SW family and may play a role in other languages, for instance, in the Northern Wakashan family which has 
not been studied here. ${ }^{14}$

\subsection{Unaccusatives}

If we accept that presence of a [+AttrTh] feature on the bound verb, then there are two assumptions that we must make in order to complete the analysis of this phenomenon. To begin with, SW has transitive, ditransitive and intransitive verbs within the lexicon. Among free verbs, both ergative and unaccusative verbs are found to occur. (20a) provides examples of unergative intransitive free verbs from all three languages and (20b) provides examples of unaccusative intransitive free verbs, also found in all three languages.
a. pisat 'run'
susaa 'swim'
b. wePič 'sleep'
qahšið 'die'

(Nuuchahnulth/Ditidaht/Makah)

The situation is slightly different for the bound verbs: bound verbs may be transitive (21a), ditransitive (21b) or unaccusative intransitive (21c), but there are no clear cases of unergative bound verbs to be found.
a. $-n a \cdot k^{w} / d a \cdot k^{w}$
have (transitive)
(N./ D./M.)
b. -ayi/ayi/iya'
give (ditransitive)
(N./D./M.)
c. -sawi $\chi /$-si wi $w /$-siwi $\chi$
die (unaccus. Intrans)
(N./D./M.)

\footnotetext{
${ }^{14}$ Sadock (1991: 108) alludes to this notion of attraction informally with respect to West Greenlandic incorporation, stating: "Since the order of elements in a West Greenlandic NP is N+modifier, this clearly shows that the incorporated N-stem is attracted to the verb".
} 
One might ask why there are no bound unergative intransitive verbs. The answer seems clear: if bound verbs are required to bear the [+AttrTh] feature, then it would, by definition, be impossible to have an unergative intransitive verb, since they must have [+Agent] subjects and no objects.

The first assumption is that transitive objects and unaccusative subjects originate in the same position, as the sister of $\mathrm{V}$. The difference between these two cases is whether the subject position is filled by an agent, as in the case of transitive verbs, or that the subject position is initially empty, as in the case of unaccusatives, which raise the theme argument into the subject position.

It may furthermore be assumed that there are unaccusative free verbs (19b) that are already saturated for the [AttrTh] feature, thereby appearing directly in the $\mathrm{V}$ position. Bound verbs may combine with $? u$ within the lexicon, subsequently being treated as any other free verb.

The difference between English bound verbs and SW bound verbs is that the former must be made free within the lexicon by wellformedness requirements. The latter, however, may be made free by combination with $? u$ within the lexicon as in English or they may be lexically inserted under $\mathrm{V}$. This then requires extraction of the leftmost element of their [+Th] argument and movement into $\mathrm{V}$ in order to fulfill wellformedness requirements.

\section{Conclusion}

One of the greatest deficiencies of previous accounts of the phenomenon under study here is the failure to consider the full scope of the complexities involved. In this paper we have seen that there are several important considerations to account for in properly 
characterizing this phenomenon. Once we examine all of the facts, from all three of the SW languages, we can have a greater sense of the challenge.

This phenomenon, that permits the extraction of an element from the sister argument of $\mathrm{V}$ and its subsequent merger with a $\mathrm{V}^{-1}$ verbal element under $\mathrm{V}$, does not involve noun incorporation of any kind, as previously suggested in the discussion in Section 2. It involves, rather, an operation of theme-attraction triggered by a feature, [+AttrTh], of bound verbs. This feature requirement may be satisfied in either of two ways: (i) morphologically, by combination with $? u$ within the lexicon or (ii) syntactically, by combination with an element of a [+Th] argument that is sister to $\mathrm{V}$.

A further important consideration in the account of this process concerns the commonalities shared by transitive and unaccusative intransitive bound verbs. With respect to the targeting of the element to combine with the bound verb, both transitive and unaccusatives behave similarly. Both seek out [+Th] arguments out of which the first element is subject to movement into the bound verb.

\section{References}

Caballero, G. et al. 2008. Nonsyntactic Ordering Effects in Noun Incorporation. Linguistic Typology 12.3, 383-421.

Chomsky, N. 1981. Lectures on Government and Binding: The Pisa Lectures. Dordrecht: Foris.

Davidson, M. 2002. Studies in Southern Wakashan (NOOTKAN)

Grammar. Ph.D. Dissertation, University of New York at Buffalo. Haas, M. \& M. Swadesh. 1931. Nitinat Field Notebooks. Philadelphia, PA: American Philosophical Society Library.

Jacobsen, W., Jr. n.d. Makah Fieldnotes. William H. Jacobsen Materials 
on Indigenous Languages of North America, SCL 2014-21, Survey of California and Other Indian Languages. MS., University of California, Berkeley.

Jacobsen, W. Jr. 1993. Subordination and Co-subordination in Nootka: Clause Combining in a Polysynthetic Verb-initial Language. In R. Van Valin, Jr. (ed.), Advances in Role and Reference Grammar 235-274. Amsterdam: John Benjamins.

Johns, A. 2017. Noun Incorporation. In M. Everaert \& H. van Riemsdijk (eds.), The Wiley Blackwell Companion to Syntax, 2nd edition. Hoboken, NJ: John Wiley \& Sons, Inc.

Katamba, F. \& J. Stonham. 2006. Morphology. Houndmills: Palgrave Macmillan.

Knipe, C. 1868. Some Account of the Tahkaht Language: As Spoken by Several Tribes on the Western Coast of Vancouver Island. London: Hatchard.

Kroeber, A. 1910. Noun Incorporation in American Languages. Verhandlungen der XVI Internationalen Amerikanisten-Kongresses 569-576. Vienna \& Leipzig: Hartleben.

Massam, D. 2017. Incorporation and Pseudo-Incorporation in Syntax. Oxford Research Encyclopedia of Linguistics. Available at <http://oxfordre.com/linguistics/view/10.1093/acrefore/978019938 4655.001.0001/acrefore-9780199384655-e-190>.

Mithun, M. 1984. The Evolution of Noun Incorporation. Language 60.4, 847-894.

Moziño, J. 1793. Noticias de Nutca, por Don José Moziño, botanico de la expedicion de N.E. y la delimites al Norte de Californias. Available at <https://brbl-dl.library.yale.edu/vufind/Record/344 7054>.

Nakayama, T. 2003. George Louie's Nuu-chah-nulth (Ahousaht) Texts with Grammatical Analysis (Endangered Languages of the Pacific Rim, A2-028). Suita: Osaka Gakuin University. 
Rose, S. 1981. Kyuquot Grammar. Ph.D. Dissertation, University of Victoria.

Sadock, J. 1991. Autolexical Syntax: A Theory of Parallel Grammatical Representations. Chicago, IL: University of Chicago Press.

Sapir, E. n.d. Fieldnotes on Nootka. In Boas Collection of the American Philosophical Society [W2a.18].

Sapir, E. 1911. The Problem of Noun Incorporation in American Languages. American Anthropologist 13.2, 250-282.

Sapir, E. \& M. Swadesh. 1939. Nootka Texts: Tales and Ethnological Narratives with Grammatical Notes and Lexical Materials. Philadelphia, PA: Linguistic Society of America.

Simons, G. \& C. Fennig (eds.). 2018. Ethnologue: Languages of the World. 21st edition. Dallas, TX: SIL International.

Stonham, J. 1998. Numerals and Incorporation in Nootka. 33rd International Conference on Salish and Neighbouring Languages 384-394.

Stonham, J. 2008. Verb-argument Composition in Nuuchahnulth: A Special Case of Denominal Verb Formation. International Journal of American Linguistics 74.4, 511-528.

Swan, J. 1870. The Indians of Cape Flattery, at the Entrance to the Strait of Fuca, Washington Territory. Washington DC: Smithsonian Institution.

Thomas, J. \& T. Hess. 1981. An Introduction to Nitinaht Language and Culture. Ms., Department of Linguistics, University of Victoria. Utrecht Lexicon of Linguistics. Available at <http://www2.let.uu.nl/UiLOTS/Lexicon/zoek.pl?lemma=Attractor\&lemmacode $=1580>$.

Wojdak, R. 2003. Pf Incorporation: Evidence from Wakashan. Paper presented at 26th GLOW Colloquium, Lund, Sweden.

Wojdak, R. 2005. The Linearization of Affixes: Evidence from Nuuchah-nulth. Ph.D. Dissertation, University of British Columbia. 